\title{
Intramural aortic hematoma: no flap no warning?
}

\section{Ematoma intramurale aortico: nessun flap, nessun allarme?}

\author{
Rodolfo Citro, Antonello Panza, Paolo Masiello, Amelia Ravera, Lucia Tedesco, \\ Rocco Leone, Marco Mirra, Roberta Giudice, Severino lesu, Francesco Silvestri, \\ Giuseppe Di Benedetto, Eduardo Bossone1
}

\begin{abstract}
Intramural aortic hematoma: no flap no warning? R. Citro, A. Panza, P. Masiello, A. Ravera, L. Tedesco, R. Leone, M. Mirra, R. Giudice, S. Iesu, F. Silvestri, G. Di Benedetto, E. Bossone.

We report a case of type $A$ intramural aortic hematoma (IMH) occurred in a 78 years old female. The clinical scenario (medical history of hypertension, severe substernal chest pain, early diastolic decrescendo murmur as for aortic insufficiency), the laboratory results (no significant troponin level), ECG and transthoracic echocardiography findings (no signs of myocardial ischemia) shifted the initial diagnostic suspicion from acute coronary syndrome to the acute aortic syndrome (AAS) and triggered further imaging tests. Computed tomography re-
\end{abstract}

\begin{abstract}
vealed an aneurismatic dilatation with thickening of the wall of the ascending aorta without intimal flap. No particular "warning message" for evidence of AAS was sent to the clinician on call. Subsequently, due to the persisting high clinical suspicion transesophageal echocardiography (TEE) was performed. TEE confirmed the aneurysm of the ascending aorta and highlighted an extended and marked aortic wall thickness, consisting with the diagnosis of type A IMH. Patient underwent urgent cardiac surgery that confirmed the diagnosis.
\end{abstract}

Keywords: intramural aortic hematoma, ascending aortic aneurysm.

Monaldi Arch Chest Dis 2011; 76: 47-49.

Department of Cardiology and Cardiac Surgery. University Hospital "Scuola Medica Salernitana", Salerno, Italy.

1 Cardiology Division Cava de’ Tirreni and Amalfi Coast Hospital, Salerno, Italy.

Corresponding author: Rodolfo Citro; Department of Cardiology and Cardiac Surgery; University Hospital "Scuola Medica Salernitana"; Heart Tower room 810. Largo Città di Ippocrate Salerno - I-84100, Italy; Phone: +39 089 673377; Mobile: +393473570880; Fax number+39089673314; E-mail address: rodolfocitro@teletu.it

\section{Case report}

A 78-year-old woman presented to the emergency room complaining of severe substernal chest pain lasting for the last six hours unrelieved by sublingual nitroglycerin. The patient was not smoker and had a medical history of systemic hypertension and hypercholesterolemia treated with angiotensin converting enzyme inhibitors (ACE-I), diuretics and statin. On physical examination heart rate was 92 beats/m, respiratory rate 20 breaths $/ \mathrm{min}$, blood pressure $180 / 100 \mathrm{mmHg}$ on the left arm vs $170 / 95$ $\mathrm{mmHg}$ on the right arm. Carotid and peripheral pulses were present and valid bilaterally. A protomesosystolic murmur (grade II/VI) followed by early diasolic decrescendo murmur (grade III/VI) on the aortic area were heard. Few bilateral basal pulmonary rales were detected on lung fields. No neurologic deficit were noted. The electrocardiogram showed sinus rhythm, left axial deviation of QRS and complete right bundle branch block. Laboratory tests performed on admission showed: hemoglobyn $10,2 \mathrm{gr} / \mathrm{dl}$, white cells $7320 \mathrm{u} / \mathrm{L}$, troponin I 0,05 (n.v. 0-0,10 $\mathrm{u} / \mathrm{ml}$ ) and D-Dimer 160 (n.v. < $250 \mathrm{ng} / \mathrm{dl}$ ) were within the normal limits while BNP 410 (n.v. $250 \mathrm{pg} / \mathrm{ml}$ ) was slightly elevated. Arterial blood gas analysis showed $\mathrm{PaO}_{2} 82 \mathrm{mmHg}$ and $\mathrm{PaCO}_{2} 41 \mathrm{mmHg}$ with $\mathrm{pH} 7,42$. Transthoracic echocardiography (TTE) revealed hypertrophic left ventricle with normal systolic function without any evidence of segmental wall motion abnormalities or pericardial effusion. Aortic root dilatation and moderate aortic regurgitation were noted. On these grounds, the initial suspicion of acute coronary syndrome was shifted towards acute aortic syndrome (AAS). A multidetector computed tomography (CT) was then performed and revealed an aneurismatic dilatation of the ascending aorta $(5,4 \mathrm{~cm})$ without intimal flap. A thickening of the aortic wall was also documented (Fig. 1); however it should be underlined that no particular "warning message" for evidence of AAS was sent to the clinician on call. Due to the persisting of chest pain without any ECG ischemic changes a second TTE followed by transesophageal echocardiography (TTE) exam was requested. The TTE/TEE confirmed the dilatation of the ascending aorta but highlighted an extended and marked aortic wall thickness at the ascending aorta level sparing the aortic root, consisting with the diagnosis of type A intramural hematoma (IMH) (Fig. 2). The patient was taken to the operating room. A median sternotomy was performed, after 


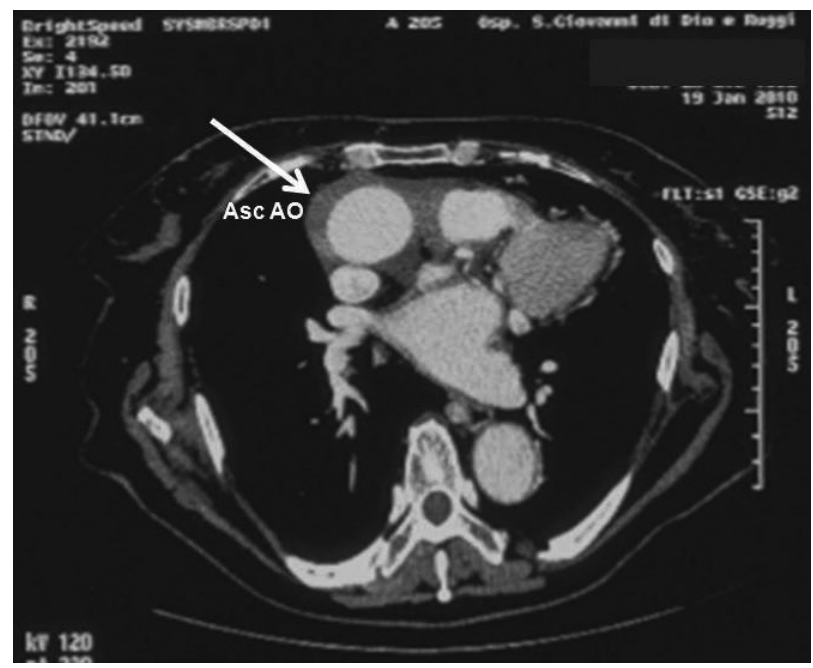

Figure 1. - Post-contrast axial CT image demonstrates aneurysm of the ascending aorta (diameter of $54 \mathrm{~mm}$ ) and crescentic thickening (arrow) of the aortic wall $(12 \mathrm{~mm})$.

partial longitudinal pericardiotomy a dilated and hemorrhagic aorta was found. Following institution of cardiopulmonary bypass and aortic cross clamping, the aorta was opened. The findings were typical of intramural hematoma (Fig. 3). No intimal flap nor tears were present. The aortic valve and coronary ostia were intact. A tubular graft Intervas- cular 30 was used to replace the ascending aorta. After 14 days of an unremarkable hospital course (except for one episode of atrial fibrillation cardioverted with i.v.amiodarone) the patient was disharged on beta-blockers, ACE-I, diuretics and statin medical therapy. At six months follow-up the patient was in generally good health; the systemic blood pressure was under control and no aortic aneurysm formation on CT scan was detected.

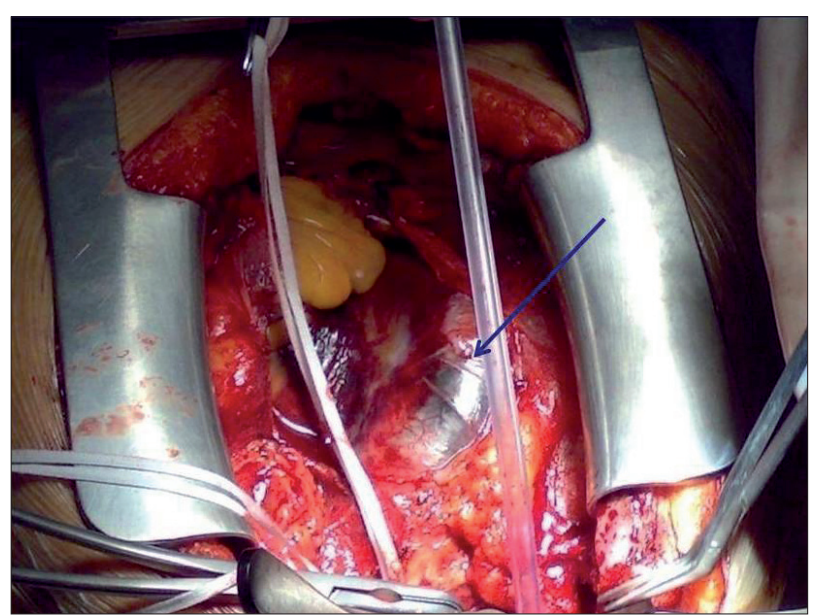

Figure 3. - Intraoperative visualization of the hematoma (see arrow) of the ascending aortic wall.
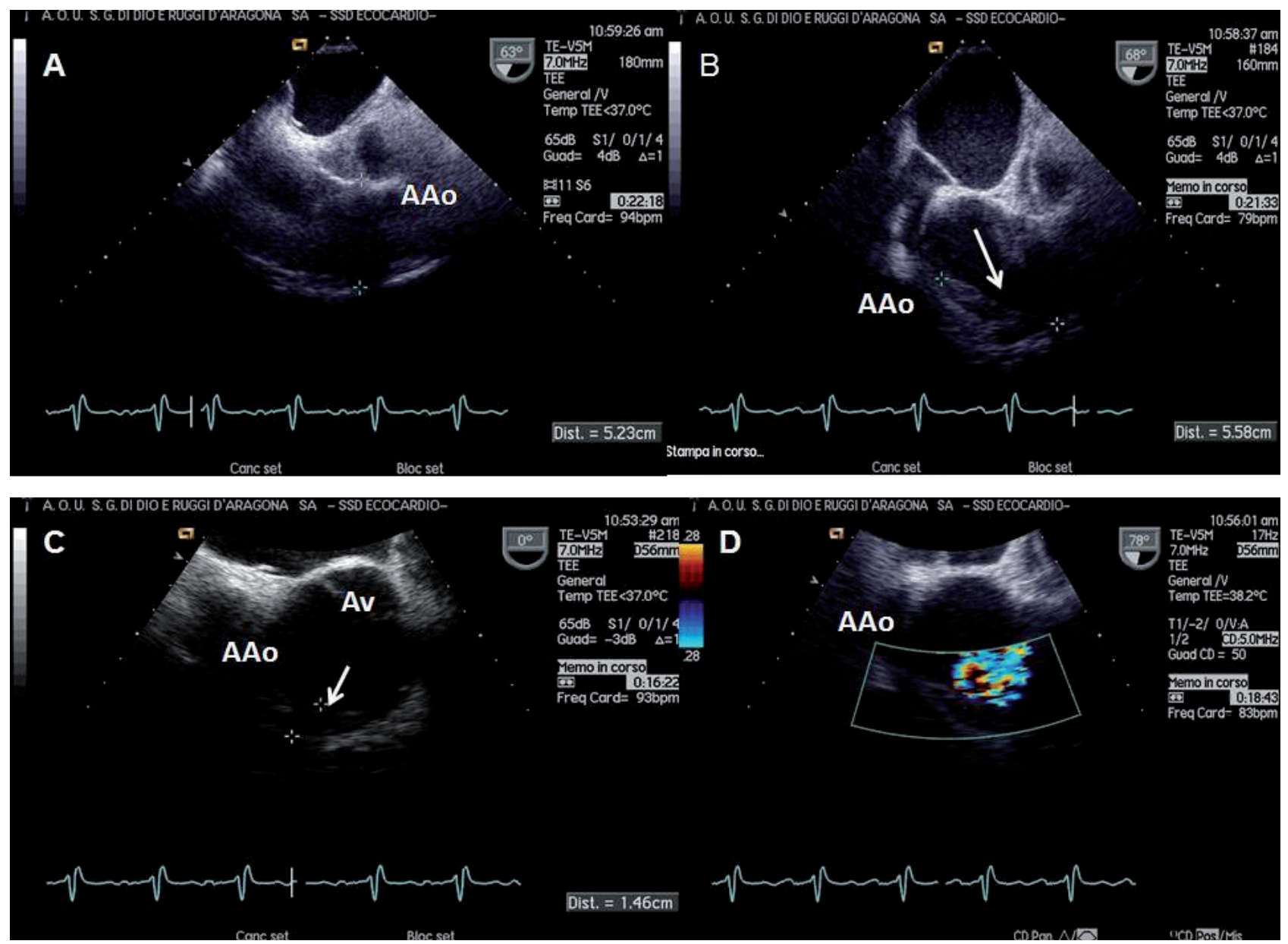

Figure 2. - A) Transoesophageal echocardiography long-axis view showing ascending aortic aneurysm; B) The ascending aortic wall thickening (arrow) extending for $5 \mathrm{~cm}$; no dissection flap or false lumen is seen; C) Marked (12 mm, see arrow), crescentic thickening of the anterior aortic wall; D) No flow within the type A IMH can be appreciated despite the low scale of color-Doppler flow mapping. (AAo= ascending aortic aneurysm; $\mathrm{Av}=\mathrm{aortic}$ valve) 


\section{Discussion}

Acute IMH is a potential fatal entity that falls under the spectrum of AAS including also classic acute aortic dissection (AAD) and symptomatic penetrating aortic ulcer (PAU) [1]. It is considered a precursor or "variant" to AAD and usually originates from ruptured vasa vasorum into the media [1$3]$. It accounts for 5 to $20 \%$ of cases presenting with symptoms of $\mathrm{AAD}$, is frequently $(50 \%-80 \%)$ located in the descending aorta and is typically associated with systemic hypertension $[3,4]$. The natural history of acute IMH continues to be debate with a regression seen in $\sim 10 \%$ of patients $[1,4,5]$. It has usually prognosis and treatment similar to AAD, with surgery recommended in patients with acute IMH involving the ascending aorta and aggressive initial medical therapy advocated in patients with type B IMH $[1,5,6]$.

When AAD is suspected, time is critical to improve survival [7]. Detection of AAS is based on clinical presentation but mainly relies on imaging techniques $[6,8]$. The different imaging modalities, such as TEE, CT and magnetic resonance imaging, employed in the diagnosis of AAS are all extremely accurate and the selection mostly depends on experience and the local availability $[6,8]$. In the emergency setting echocardiography is safe, fast, and readily available. It can be performed without delay in patients with suspected AAS, to evaluate the presence or absence of several important features such as intimal flap and false lumen for $\mathrm{AD}$, saccular aneurismal formation for PAU and aortic wall thickness for IMH. Moreover echocardiography is useful to guide differential diagnosis excluding other pathologies such as acute coronary syndrome, pericarditis, and pulmonary embolism. Transesophageal echocardiography has, compared with TTE, higher sensitivity (94-100\% vs 59-83\%) and specificity (77-100\% vs $63-93 \%)$ respectively for identifying an intimal flap, classic sign of aortic dissection. Therefore, a high index of clinical suspicion and the rapid availability of diagnostic tests that are safe, sensitive, and specific are required to make the correct diagnosis and identify those patients who need early surgery. In the International Registry of Acute Aortic Dissection (IRAD) CT scan was used most frequently as the first test in $61 \%$ of cases, and TTE or TEE as a secondary technique in $56 \%$ of cases with an average of 1.8 methods for each patient [6]. We have to keep in mind that the absence of intimal flap exclude only the absence of aortic dissection, but not the other form of AAS, such as the IMH. As in this case and according to the IRAD recommendations, when the diagnosis is elusive despite an high clinical suspicion of AAS clinicians should not hesitate to use more than one imaging modality. Moreover, increment of D-Dimer has been associated to the AAS expecially AD, but it should be underlined that the lack of elevation of D-dimer level does not exclude the presence of IMH [9]. Finally, careful clinical and imaging long term monitoring is essential in order to detect early signs of disease progression or aneurysm formation and to achieve optimal blood pressure control.

\section{Riassunto}

Riportiamo un caso di ematoma intramurale dell' aorta di tipo A in una donna di 78 anni. Lo scenario clinico (storia di ipertensione arteriosa, dolore retrosternale urente, soffio diastolico in decrescendo da insufficienza aortica), $i$ dati laboratoristici (assenza di incremento significativo della troponina), $i$ dati dell'ECG e dell' ecocardiografia trans toracica (non mostravano segni di ischemia miocardica) hanno modificato il sospetto diagnostico iniziale da sindrome coronarica acuta a sindrome aortica acuta (AAS) e avviato ulteriori indagini con test di imaging. La TC rivelava una dilatazione aneurismatica con ispessimento della parete dell'aorta ascendente senza "flap" intimale. Nessun particolare "messaggio di allarme" di sindrome aortica acuta veniva trasmesso al clinico. Successivamente, per il persistere di un elevato sospetto clinico, veniva eseguita una ecocardiografia transesofagea (TEE). La TEE confermava l'aneurisma dell'aorta ascendente, visualizzando un esteso e marcato ispessimento della parete aortica, compatibile con diagnosi di ematoma intramurale dell' aorta di tipo A. La paziente veniva avviata ad intervento cardiochirurgico, che confermava la diagnosi.

\section{References}

1. Tsai TT, Nienaber CA, Eagle KA. Acute aortic syndrome. Circulation 2005; 112: 3802-3813.

2. O' Gara PT, De Sanctis RW. Acute aortic dissection and its variants: toward a common diagnostic and therapeutic approach. Circulation 1995; 92: 1376-1378.

3. Evangelista A, Mukherjee D, Mehta RH, et al. Acute intramural hematoma of the aorta: a mystery in evolution. Circulation 2005; 111: 1063-1070.

4. Maraj R, Rerkpattanapipat P, Jacobs LE, Makornwattana $\mathrm{P}$, Kotler MN. Meta-analysis of 143 reported cases of aortic intramural hematoma. Am J Cardiol 2000; 86: 664-668.

5. Evangelista A, Dominguez R, Sebastia C, et al. Longterm follow-up of aortic intramural hematoma: Predictors of outcome. Circulation 2003; 108; 583-589.

6. Hiratzka LF, Bakris GL, Beckman JA, et al. Guidelines for the diagnosis and management of patients with Thoracic Aortic Disease. Circulation 2010; 121(13): e266-369.

7. Hagan PG, Nienaber CA, Isselbacher EM, et al. The International Registry of Acute Aortic Dissection (IRAD): new insights into an old disease. JAMA 2000; 283: 897-903.

8. Erbel R, Alfonso F, Boileau C, et al. Diagnosis and management of aortic dissection: task force report of the $\mathrm{Eu}-$ ropean Society of Cardiology. Eur Heart J 2001; 22: 1642-1681.

9. Suzuki T, Distante A, Zizza A, et al. IRAD-Bio Investigators. Diagnosis of acute aortic dissection by D-dimer: the International Registry of Acute Aortic Dissection Substudy on Biomarkers (IRAD-Bio) experience. Circulation. 2009; 119: 2702-2707. 